\title{
sciendo
}

\section{Monitoring of Educational Programs for the Development of Professional Competencies by Procurement Specialists in Procurement Statistics}

\author{
Svetlana A. Sergeeva \\ Moscow State Institute of International Relations (MGIMO), \\ Moscow, Russia
}

Doi: 10.2478/ajis-2019-0035

\begin{abstract}
Development of professional competence of the procurement specialists in procurement statistics is one of the research priorities in the supply of human resources for procurement. State priorities in the training of personnel ready for efficient professional activity in the ever changing environment are reflected in the content of educational programs. But the lack of uniform requirements for the training of managers, specialists and experts in the field of procurement gives rise to a huge number of problems. Digitalization of procurement, growth of e-commerce requires mandatory introduction of such a component as procurement statistics into the structure of professional competence of customers. But how to determine the necessary amount of knowledge, which statistical tools should be in possession of a graduate of the educational program - these and many other questions remain open. This paper presents the main approaches to the development of professional competencies of procurement specialists in maintaining statistical records of the procurement activities through educational programs based on monitoring of their efficiency.
\end{abstract}

Keywords: procurement statistics, educational programs, monitoring, professional competencies, development

\section{Introduction}

The idea of the most efficient development of the system of public procurement at this stage is based on a variety of principles that underlie the evolvement of the procurement system of the state and imply the shortest lead time to meet the needs of the state with the goods and services of the highest quality funded by the state budget. Public procurement is one of the priorities of sustainable development of the domestic economy. Staffing of the procurement sector requires the ongoing updating of the content of professional competence of managers, specialists and experts in the field of procurement (Gladilina \& Svarnik, 2017). With introduction of the elements of procurement digitization the requirements for statistical data handling are getting tougher. The principle of professionalism of the customer, which implies the involvement of qualified specialists with theoretical knowledge and skills, as well as the measures aimed at maintaining and improving their skills and professional education in general and in statistics in particular is one of the leading principles of staffing the procurement sector, since it is the professionalism of persons involved at all stages of the procurement that predetermines the efficiency of each purchase (Gladilina \& Svarnik, 2017).

In the modern models of personnel management, the level of qualification of specialists may be assessed from the point of view of development of their professional competence that nominally may be regarded as their ability to apply the acquired skills and knowledge specific to the occupation when implementing certain professional tasks. As regards the procurement specialists, with account of the high social significance of public procurement, a need arises to assess their 
professional competence in a comprehensive way. Monitoring of the level of professional competence of procurement specialists in maintaining procurement statistics is a rather complicated process (Sergeeva \& Arionchik, 2016). As concerns the practice of monitoring the level of professional competence, the foreign scientific literature explores the need to conduct surveys and to record non-quantitative indicators of changes in the level of competence of employees and to increase their potential by implementation of programs for the nurturing and development of competence (Antonova, 2016; Semenova et al., 2016; Draskovic et al., 2017).

Orientation towards personal and occupational potential, personal attitudes, abilities and motivation of the employee may be regarded as the main difference between the competencebased approach in staff management and the traditional ideas. Targeted work with the hidden and overt capabilities of employees in the system of public procurement contributes to the sustainable growth of their professionalism, and, as a result, to their higher personal satisfaction with work and emergence on this basis of a continuous need to improve their own level of competence.

\section{Literature Review}

Public procurement, given its importance in the economy of the whole country, is given great attention in the economic literature. According to a number of researchers, the most effective spending of funds from the state budget is a very important problem for any state, so the optimization of the procurement system for the needs of the state is a priority in the system of state budgeting (Belokrylova, 2016; Gladilina et al., 2015).

The system of procurement for the needs of the state has a huge impact on the functioning of the entire state, the satisfaction of public demands, the work on public projects (Gushchin, 2012). Procurement for the needs of the state is an important regulator of economic and social processes, the role of which is very important for any economic system, including the insufficiently stable ones, which is relevant for the Russian Federation (Belokrylova, 2016).

When studying the development of the procurement system for the state, A.A. Demin (2007) came to the conclusion that the procurement system is part of the produced services and goods, which are purchased by the government and public entities using the funds from the state budget. K.V. Kuznetsov (2005) believes that purchases for the needs of the state are carried out on the basis of the state budget to ensure the work and life of the state entities, except for purchases with a view of further reselling of services or goods.

The high significance of procurement in meeting state, municipal and corporate needs in Russia has required new approaches to the training of procurement specialists. As of today, the requirements have been defined for qualifications, length of service and level of education of employees in the field of public procurement, based on the specifics of professional duties. In general, they may be summarized as follows:

1. Analytical and informational work to support the required procedures and regulations in the unified information system of public procurement.

2. Planning of procurement procedures, data forecasting and updating in the unified information system.

3. Work with claims and appeals against the results of public procurement.

4. Implementation of procurement procedures.

5. Consulting and methodical guidance in the field of planning and support of competition in the course of procurement for the needs of the state.

6. Other functions relevant for the efficient spending of funds from the state budget.

Thus, a review of the scientific literature on the importance of procurement for the development of any state allows us to conclude that there is a need for supply of professional resources to the procurement sector (Antonova, 2016; Gladilina \& Svarnik, 2017; Abramova \& Tkachenko, 2015; Lyons \& Jillingham, 2014; Semenova et al., 2016). Monitoring of the level of professionalism of the specialists in the field of procurement is based on the use of the models for staff evaluation. By way of example, let's consider the Donald Kirkpatrick's model, according to which there are four main levels for assessing efficiency of training and development programs for the employees: 
1. Reactions - instant feedback from participants after the learning or developing event in order to assess their impressions of the specific program components.

2. Learning - evaluation of changes in the knowledge and skills of the development program participants, which methods may vary from formal testing to group and individual evaluation.

3. Behavior - use of the acquired knowledge and skills in everyday life and on their job, in other words, demonstration of the acquired competence when completing professional tasks.

4. Results - changes that have occurred after implementation of the staff development program, including improvements in performance indicators, reduced staff turnover and others (Kirkpatrick D.L. \& Kirkpatrick J.D., 2009).

In order to quantify the return on investment for staff development programs and to obtain a more coherent picture of their effectiveness, the fifth level offered by D. Phillips (2012) can be added to the four levels of D. Kirkpatrick (Kirkpatrick D.L. \& Kirkpatrick J.D., 2009), which is a ROI indicator in the form of a coefficient:

$$
R O I=\frac{\text { Training effect }- \text { Costs for training }}{\text { Costs for training }} \quad * 100 \%
$$

While for the employees whose deliverables cannot be identified, it is proposed to use the indicator of alternative costs for attracting a new employee to the current position or to the position sought by an evaluated employee after completion of the planned activities. This leads to modification of ROI indicator based on the previously examined options:

$$
R O I=\frac{\text { (Alternative costs for attracting a new employee) }- \text { Costs for training }}{\text { Costs for training }} * 100 \%
$$

The Kirkpatrick-Phillips model, which includes five evaluation stages for the competence development program, allows us to assess both quantitative and qualitative indicators of employee qualification improvement and to evaluate the efficiency of the employee training and competence development system. The analysis of scientific literature and practices of monitoring the level of certain professional competencies of specialists in the field of procurement and professional competencies in the field of procurement statistics gave us the grounds to consider one of the efficient models, the model that measures the degree to which the welfare of a specialist has been favoured, the G. Becker's model (1975). In his research on investment in human capital, G. Becker (1975) examined the positive effect of employee training, which increases the employee's professional attractiveness both for a particular organization and in the labor market. An adapted model reflecting the employee's assessment of the impact of training by comparing its salary before and after the training:

$$
\sum_{0}^{t_{1}} \frac{W_{t}^{*}-W_{1 t}}{(1+r)^{t}}<\sum_{t_{1}}^{T} \frac{W_{2 t}-W_{t}^{*}}{(1+r)^{t}}
$$

where $W^{*}$ is the salary when the employee is not trained, $W_{2 t}$ is the salary of the employee after training, $W_{1 t}$ is the salary of the employee during training, $\mathrm{T}$ is the length of subsequent employment, $r$ is the percentage rate.

In this case, the salary rate, based on the model assumptions, should be higher than what the employee received before the training, otherwise the training program will be considered ineffective. However, in the current circumstances in Russia, additional training does not guarantee that the employee will be promoted or will get a salary increase, so it is not correct to assess efficiency of the competence development programs by the employee's welfare, and among other reasons also because the skills and knowledge that form the competencies cannot be easily assessed from the economic perspective without consideration of specific goals and objectives.

The approach to evaluating efficiency of the competence development programs by an economic entity based on the use of financial indicator Return On Investment (ROI) has become widespread (Duncan, 2019). This indicator is traditionally used in investment activities, so the competence development and qualification improvement program is viewed in the broad sense as investment in the professionalism of employees. But quantifiable investments require a specific 
quantitative assessment of the result, for example, the budget savings achieved in public procurement. ROI in any of these variations may be used only when it is possible to clearly measure and evaluate the result (Kaminski \& Lopes, 2009):

$$
R O I=\frac{\text { (Benefit }- \text { Cost }) * 100 \%}{\text { Cost }}
$$

where Benefit is the benefit of implementation of the initiative, e.g. total budget savings upon achievement of procurement goals and objectives (when applied to the competence development programs, it represents the difference between the evaluated indicator "after" and "before" implementation of the program), cost is the cost of the initiative, e.g. the cost to implement a competence development program.

In a simplified form, the formula may be written as follows:

$$
R O I=\frac{\text { Benefits from training }}{\text { Costs for training }} * 100 \%
$$

When the ROI is greater than one, the competence development program is considered to be successful because the economic benefits of its implementation exceed the costs incurred.

The practical use of $\mathrm{ROI}$ indicator is demonstrated by Chronus: Mentoring \& Talent Development Solutions in an extended version which takes into account the peculiarities of investment in the development of competence potential of the employees rather than some abstract investment project (Duncan, 2019):

$$
R O I=\frac{R+(E+A)}{P},
$$

where $R$ (retention) is the alternative cost to replace employees, $E+A$ (engagement and advancement performance) is the benefits brought by the "engaged" employees, and $\mathrm{P}$ (program cost) is the program implementation cost.

A general overview of the structure of efficiency evaluation of competence development programs in the public procurement system may be presented as follows:

1. Identification of the main items which are the target of analysis and calculation of performance indicators;

2. List of indicators and criteria characterizing efficiency of the competence development program;

3. Collection, compilation and systematization of data on the program evaluation procedures and data as necessary to measure certain indicators and criteria;

4. Description of the mix and essence of the program's structural components enabling collection of the necessary information;

5. A plan and program of activities for the evaluation of the program component specifying associated timing and needed resources for the forthcoming evaluation of the program efficiency.

When carrying out evaluation studies, it is important to bear in mind that the competence development program has different components, each with its own dedication and purpose. That's why each evaluative observation should be developed and planned separately for each event. Within one group of events or one component of the program, similar efficiency evaluation methods may be used, such as employees interviewing after training and learning events using specific templates, or a method of collecting feedback from supervisors on the success of their subordinates before and after the training event. In order to achieve a lasting effect of a range of events, the acquired competencies, skills and knowledge need to be maintained and developed over a long period of time, and therefore the discussion by the managers and their subordinates of their competencies six months or a year after the conducted training event will increase the motivation of employees for self-development and involvement in the process of training and building the necessary competencies. Today in Russia the development of professional competencies of procurement specialists in statistical measurement of the volume of procurement, methods for selection of suppliers, etc., is a pressing concern, which requires the solution to both a problem of building such of competence, and a problem of monitoring their level. Important to note here, that monitoring should be performed not for the sake of monitoring, but for development of individual 
educational trajectories.

\section{Research Methodological Framework}

The research objective: based on the analysis of theory and practice of developing professional competencies of the employees engaged in procurement activities, validate the necessary and sufficient institutional conditions for the development of professionalism of procurement specialists in maintaining procurement statistics through educational programs.

The research tasks as covered by this paper:

1. Examine Russian and foreign experience in implementation of competence approach to raising professionals for the procurement sector.

2. Consider modern models for evaluating efficiency of staff training and development programs.

3. Validate the main approaches to the development of professional competence of procurement specialists in maintaining statistical records of the procurement activities through educational programs.

The methodological basis of the research is constituted by scientific approaches to economic and managerial substantiation of conclusions and recommendations, which offer solution to the scientific problem of the development of professional competencies of procurement specialists in maintaining procurement statistics.

The research is relying on the analysis of the current models for evaluating efficiency of staff training and development programs, as well as the procurement practices based on the following methodological principles: unity of theory and practice, purposefulness, efficiency, consistency.

\section{Findings and Discussion}

Professional competencies of procurement specialists in the field of procurement statistics in the context of digitalization gain special importance - conversion of large data into digital form with a possibility to use this data both in the current mode and in the long run requires special training and building of the new content of professional competencies. In foreign and Russian practice, a competency-based approach is an integral part of staff management in all areas of activity. The employees are treated as an asset of strategic value. They possess certain competencies, i.e. models of behavior, skills and knowledge as required for the most efficient accomplishment of professional goals and objectives.

The essence of the competency-based approach may be defined as a redistribution of managerial tasks by employees from the idea on how to solve current problems with personnel (for example, by professional development of employees or replacement of managers) to the tasks of strategic paradigms, which are beyond the daily staff management tasks (Chulanova, 2014). It can be observed that this approach brings a regular increase in the level of professionalism, knowledge base, improvement of professional skills, behavior and level of competencies of the employees, which in turn leads to higher efficiency of the entire system. The idea of competency-based approach encompasses the main objectives of personnel management that are underpinned by identification of changes in the organization performance and achievement of higher professional results, positive shifts in the behavior of employees, increased productivity and efficiency of public procurement (Polbitsyna, 2015).

The competency-based approach is efficiently implemented in relation to employees of the procurement system. The procurement employees should have a specialized higher or supplementary vocational education. These requirements at the level of legislation are determined on the basis of explanation by the Ministry of Economic Development (N OG-D28-15539) which establishes no specific requirements for an employee of the public procurement system. Article 112 of the Law 44-FZ states that the customer may appoint an employee who has received education not as a procurement specialist, but as a specialist in the field of orders.

Some researchers believe that the major impact on evolvement of a specialist is exerted by his/her experience and level of qualification. The acquired skills, competencies and knowledge may 
be adapted and modified for more efficient accomplishment of professional tasks (Leibnovych, 2012).

As a result, the following basic stages in the implementation of educational programs are essential for the development of professional competencies of specialists and managers of the procurement system for the needs of the state:

- General education consisting of primary and secondary education through which a person gains primary skills and knowledge;

- Higher education and acquisition of basic competencies necessary for professional growth.

- The acquired competencies should be proven with the certificates of education. For improvement of the quality of education, the educational institutions should correspond to all state standards. The framework of normative and legislative regulations, relevant for educational institutions, contains:

- a system of control over compliance with all requirements related to the standards of education and assessment of the level of their implementation, the efficiency of the training process;

- quality standards, education standards specifying requirements to the educational programs, the necessary competencies;

- organizational system responsible for analyses and monitoring of compliance with standards.

The level of professionalism of procurement specialists in maintaining procurement statistics is influenced by educational programs that contain such training methods as (Karmanov \& Sergeeva, 2017):

Methods outside the workplace:

- Training using the latest IT developments (online training) implying a broad use of interactive solutions;

- Traditional teaching in the lecture format, passive learning having a number of drawbacks, such as student fatigue and lack of interaction with the lecturer;

- Enhancement of the level of qualification and professionalism by performing a number of tasks aimed at developing creative skills, logical thinking and methods of critical assessment of emerging problems (discussion clubs, clubs by professional interests, etc.);

- Trainings, seminars, conferences, i.e. training through problem solving in a group;

- Obtaining professional competences by modeling processes and situations in the applied paradigm (solving economic and production issues by modeling and analysis of similar situations);

- Role-based training, which implies development of approaches to behavior in case of critical situations, training in negotiation tactics and corporate interactions;

- Individual consulting on specific issues.

Methods within the workplace:

- Induction training, workplace introduction, explanation of work technology and work conditions, adaptation to the working environment;

- Acquisition and improvement of practical skills, including irregular training and the development of an individual professional improvement plan;

- Cooperation between employees, including mentoring;

- Staff rotation, i.e. increase of professional potential by ranking the employees between subdivisions and study of similar tasks and functions.

From the point of view of assessment of the efficiency of development of professional competencies of procurement specialists in maintaining procurement statistics in the context of digitalization, in our opinion, modifications to traditional indicators characterizing the effectiveness of measures may be applicable.

Thus, the above mentioned parameters give an opportunity to carry out fast and deep monitoring of educational programs for development of professional competencies of procurement specialists in the field of statistics. However, the result gets identified only in the long run and 
thorough research work taking into account the specific aspects of each problem block is needed to determine the causes of deviation from the expected results.

\section{Conclusion}

As evidenced by the modern procurement practices, it is impossible to operate on the principle of customer professionalism in the public sector if the number of employees with high professional potential is insufficient. As for the development of professional competences of procurement specialists in the field of statistics, employees should have a clear motivation, sufficient qualification, relevant competences. Personal and professional potential of employee is a key parameter to further improvement of professionalism in maintaining procurement statistics.

Implementation of the system of requirements to the necessary education of the procurement specialists in the field of statistics gives the necessary tools for the practical use of the paradigm of professionalism on behalf of the customer and achievement of objectives and goals with regard to improvement of the procurement system for the needs of the state. Monitoring as a management approach creates a system of requirements for the necessary skills, knowledge and level of qualification of the procurement employees, which is inseparable from the policy of strategic development of the procurement system.

\section{Acknowledgements}

The reported study was funded by RFBR according to the research project N 17-02-50115.

\section{References}

Abramova, E., \& Tkachenko, B. (2015). Public procurement: directions of development. Review of international practices and analysis of situation in the Russian Federation. Moscow: Sector.

Antonova, Yu.V. (2016). Foreign experience of public procurement in developed countries. Economics. Ivanovo, 7(16). Retrieved from https://cyberleninka.ru/article/n/mezhdunarodnyy-opyt-gosudarstvennyh-zakupok-vrazvityhstranah on January 10, 2019.

Becker, G.S. (1975). Investments in Human Capital: Effects on Earnings. Human Capital: A Theoretical and Empirical Analysis, with Special Reference to Education, Second Edition (pp. 13-44).

Belokrylova, O.S. (2016). Institutional modernization of the public procurement system: Risk zones. State and Municipal Management. Scientific Notes of SKAGZ, 4, 21-29.

Chulanova, O.L. (2014). Personnel management based on competencies: Monograph. Moscow: INFRA-M.

Demin, A.A. (2007). State order as a development factor of the public sector of transformational economy: theoretical and economic aspects: PhD thesis abstract. Chelyabinsk.

Draskovic, M., Milica, D., Mladen, I., \& Chigisheva, O. (2017). Preference of Institutional Changes in Social and Economic Development. Journal of International Studies, 10(2), 318-328.

Duncan, A.C. (2019). Talent Development: The ROI of mentoring, coaching, and other employee development programs. Retrieved from https://www2.usgs.gov/humancapital/ecd/mentoringreadinglist /CoachingMentoringDriveSuccess.pdf on January 10, 2019.

Gladilina, I.P., Degtev, G.V., \& Sergeeva, S.A. (2015). Life Cycle Contracts in the Development of Procurement in the Russian Federation: World Experience. Asian Social Science, 11(14), 343-348.

Gladilina, I.P., \& Svarnik, T.A. (2017). Fundamentals of competency-based approach in training managers for procurement. Innovations and Investments, 12, 109-111.

Gushchin, A.Yu. (2012). Measuring efficiency and methods for its assessment in the public order system. Fundamental Researches, 9, 204-208.

Kaminski, K., \& Lopes, T. (2009). Return on Investment: Training and Development. Society for Human Resource Management (SHM). Alexandria. Retrieved from https://www.shrm.org/academicinitiatives /universities/teachingresources/documents/09-0168\%20kaminski\%20roi\%20tnd\%20im_final.pdf on February 20, 2019.

Kuznetsov, K.V. (2005). Competitive purchases: bidding, tenders, contests. Peter.

Karmanov, M.V., \& Sergeeva, S.A. (2017). Relevant issues of the development of public procurement statistics: article. Bulletin of the Moscow Government University: Research and Practice Journal of Moscow City Government University, 1, 20-25. 
Kirkpatrick, D.L., \& Kirkpatrick, J.D. (2009). Evaluating training programs. San Francisco: Berrett-Koehler Publishers.

Leibnovych, A.N. (2012). Methodology and policy for the development and application of the National Qualifications System. Education and Science, 4. Retrieved from http://edscience.ru/ru/article/n-leybovich on February 15, 2019.

Lyons, C., \& Jillingham, M. (2014). Procurement and Supply Chain Management. Moscow: Infra.

Phillips, J.J. (2012). Return on Investment in Training and Performance Improvement Programs. ButterworthHeinemann.

Polbitsyna, L.G. (2015). Professionalism of the customer as a necessary condition for optimization of the state and municipal procurement. Municipality: Economy and Management, 1(10), 49-54.

Semenova, F.Z., Borlakova, M.B., \& Botasheva, L.S. (2016). Foreign experience in organizing public procurement. Fundamental Researches, 6-2, 465-469.

Sergeeva, S.A., \& Arionchik, A.A. (2016). Statistical Studies of Non-Price Competition in the Structure of Public Procurement in the Russian Federation. Journal of Internet Banking and Commerce, 21(S4). 